\title{
Perspectiva del cuerpo humano en san Agustín
}

\author{
I NTRODUCCION
}

San Agustín desarrolla su reflexión indagatoria sobre el cuerpo humano desde dos ángulos bastante definidos: 1) desde una perspectiva filosófica; 2) desde una perspectiva teológica. El primer punto de vista toma como fuente la propia realidad, es decir, realiza una lectura descriptiva donde simplemente se ponen de relieve las características o determinaciones del objeto cuerpo humano. Esta perspectiva filosófica, a su vez, asume dos modos de consideración: a) modo sensible; b) modo racional o inteligible. El modo sensible de leer la realidad constituye para san Agustín el dato o elemento que encuentra como punto de interpretación. Este dato o primer indicio constituye el mundo de lo visible, captable solamente por los "ojos de la carne" o del propio cuerpo. Aquí, la perspectiva filosófica, cumple una mera función indagadora o protoelaborativa; simplemente registra el material, en cierta manera ya elegido, para la futura interpretación conceptual. Previa esta tarea se ingresa en el segundo modo de perspectiva filosófica, el racional o inteligible. En él se indaga por la esencia de las cosas o, dicho de otra manera, se plantea lo real únicamente desde su estructura inteligible anulando todo posible resabio de dato sensible; es una manera de considerar los objetos en sus últimas relaciones inespaciales e intemporales. Pero este modo de operar con las cosas sólo es posible reflexionando a la luz de los "ojos del alma" u "ojo interior", que percibe exclusivamente lo inmaterial o invisible. Es un ver la realidad desde el punto de vista de la eternidad ya admitida primariamente. El "ojo interior" me descubre el mundo de las relaciones que rigen al ente $y$ cuya perpetuidad linda con el foco de la Verdad. Al "ojo del al- 
ma" se llega, según san Agustín, con esfuerzo y preparación mediante la ejercitación y el adiestramiento previos del propio pensamiento, que descubre y patentiza la visión de este mirar de la razón o mirar interno; este modo de perspectiva filosófica señala que se supone una concepción de la filosofía como saber purificador o desembarazante que refuerza la participación y el apropiamiento de la Verdad Eterna, lograda primariamente por otro camino ${ }^{1}$. La labor filosófica explicita racionalmente la Suprema Verdad Inteligible que se nos ha brindado, en forma evidente, por intermedio de la fe. La fe muerde a través de la Palabra revelada, los hitos constitutivos de esa Verdad. La filosofía entonces obra simplemente como apéndice o prolongación adecuada de la Teología ${ }^{2}$. Por si mismo el saber filosófico no puede llegar a una comprensión unívoca o autosuficiente del ser. La creencia fundamenta el conocer. De acuerdo a esto la reflexión filosófica se canaliza a través de un método dialéctico que oscila entre lo sensible y lo inteligible, la sensación y la razón, lo que permanece y. lo que perece y lo visible y lo invisible. Esta oscilación o marcha pendular entre contrarios se resuelve o absorbe en una hermenéutica englobante que se estructura desde la propia Verdad Eterna a través de la

1. Podemos decir que los grandes temas de la reflexión agustiniana son Dios, el alma y la felicidad eterna. Su especulación en este sentido, está inspirada por un anhelo ascensional: "Unum est quod tibi possum praecipere, nihil plus novi. Penitus esse ista sensibilia fugienda cavendumque magnopere, dum hoc corpus agimus, ne quo eorum visco pennae nostrae impediantur, quibus integris perfectisque opus est ut ad illam lucem $a b$ his tenebris evolemus: quae se ne ostendere quidem dignatur in hac cavea inclusis nisi tales fuerint ut ista vel effracta vel dissoluta possint in auras suas evadere. Itaque quando fueris talis ut nihil te prorsus terrenorum delectet, mihi crede, eodem momento, eodem puncto temporis videbis quod cupis" (Soliloquia, I, XIV, 24).

En esta marcha ascensional distingue entre Ciencia y Sabiduria: la ciencia es la que estudia las cosas humanas y temporales; la sabiduría se refiere estrictamente a las cosas divinas: "Si ergo haec est sapientiae et scientiae recta distinctio, ut ad sapientiam pertineat aeternarum rerum cognitio intellectualis; ad scientiam vero temporalium rerum cognitio rationalis; quid cui praeponendum sive postponendum sit, non est difficile iudicare" (De Trinitate, XII, XV, 25).

Las presentes citas y todas las que se transcribirán corresponden a las Obras de San Algustin, Biblioteca de Autores Cristianos, Madrid, MCMXLVI, .. MCMXLVII, MCMXLVIII y MCMLXVIII, Tomos I, II, III, V y VII.

2. Dice San Agustín: "Ut ergo ab huiusmodi falsitatibus humanus animus purgaretur, sancta Scriptura parvulis congruens, nullius generis rerum verba vitavit, ex quibus quasi gradatim ad divina atque sublimia noster intellectus velut nutritus assurgeret". (De Trinitate, I, I, 2). 
Revelación ${ }^{3}$. Teniendo en cuenta el esquema señalado que creemos responde al pensar agustiniano, pasamos a esbozar su perspectiva del cuerpo humano.

1) Perspectiva filosófica: modo sensible o lectura primaria de la realidad (dato).

a) San Agustín expresa, en primer término, que lo corpóreo en general es lo que está limitado y circunscrito por una forma y por una especie, figura, de naturaleza material y grosera que remeda y aspira, en cierta manera, a la verdad ${ }^{4}$. En este sentido lo corpóreo propiamente dicho es imitación de algo; es, al parecer, no consistente, falso. En este horizonte se enclava la reflexión agustiniana sobre el cuerpo humano. Asi el cuerpo terreno es un compuesto de los cuatro elementos: aire, tierra, agua y fuego; es la forma visible del hombre como objeto que ocupa un espacio. En relación con esta determinación espacial del cuerpo terreno, san Agustín lo cualifica como especie de "hinchazón" que rodea al alma que aumenta y disminuye según el transcurrir temporal. Este aumento puede ser: "necesario", cuando los miembros cons" titutivos del cuerpo humano terreno crecen en su proporción adecuada; "superfluo", cuando éstos o, mejor dicho, cuando uno de sus miembros crece desproporcionadamente sin resentir la salud y, "dañoso", cuando en el cuerpo se desarrolla algo que va contra la buena salud, por ejemplo un tumor. Desde esta descripción

3. En este aspecto existe una armonia absoluta entre razón y fe: "Mihi autem certum est nusquam prorsus a Christi auctoritate discedere; non enim reperio valentiorem: Quod autem subtilisima ratione persequendum est (ita enim iam sum affectus, ut quid sit verum, non credendo solum sed etiam intelligendo apprenhendere impatienter desiderem)" (Contra Academicos, III, XX, 43).

"Nisi credideritis, non intelligatis" (De Libero Arbitrio, II, II, 6).

4. Sin embargo, a pesar de esta su naturaleza material y grosera no deja de ser un bien. Existe una Bondad en todo lo existente en el Universo, que expresa el reflejo trinitario (vestigium Trinitate): "Haec itaque tria, modus, species et ordo, ut de innumerabilibus taceam, quae ad ista tria, pertinere monstrantur; haec ergo tria modus, species ordo, tanquam generalia bona sunt in rebus a Deo factis, sive in spiritu, sive in corpore. Deus itaque supra omnem creaturae modum est, supra omnem speciem, supra omnem ordinem; nec spatiis locorum supra est, sed ineffabili el singulari potentia, a quo omnis modus, omnis species, omnis ordo. Haec tria ubi magna sunt, magna-bona sunt; ubí parva sunt, parva bona sunt: ubi nulla sunt, nullum bonum est. Et rursus ubi haec tria magna sunt, magnae naturae sunt; ubi parva sunt, parvae naturae sunt: ubi nulla sunt, nulla natura est. Omnis ergo natura bona est". ( $D e$ Natur. Boni. Contra Manichaeos, I, 3). 
temporal también afirma que envejece y que inclusive es algo que se puede perfecionar. De las determinaciones expuestas podemos concluir que el cuerpo sería una figura tridimensional llena de materia; esta materia posee, a su vez, una forma o configuración que para San Agustín es superior a la propia magnitud y también una determinación muy importante, el peso (pondus). El cuerpo es además una especie de máquina traspasada en todas direcciones por los nervios, conductos que el alma usa, para ponerla en funcionamiento; en este sentido describe al cuerpo como "utensilio" o instrumento del alma. Entonces, figura espacio temporal de materia y forma que no siempre nos muestra el mismo dibujo y que sirve como medio o instrumento de una entidad extraña a él: el alma. Esencialmente es un ser-para aquí y ahora y no un ser en sí mismo.

Al principio, decíamos, lo describe como compuesto de los cuatro elementos. Es preciso decir ahora que entre esos cuatro elementos establece una profunda cohesión o armonía que consiste esencialmente en ser proporción u ordenación ${ }^{5}$. Cuando la armonía pasa a ser desequilibrio, desarmonía, es porque el alma ha salido de él alterándose la proporción entre su partes constitutivas aire, tierra, agua y fuego. La presencia del alma lo mantiene en su unidad y cohesión y no sólo ésto sino que el alma en su primer grado de realidad le da animación y lo unifica. El cuerpo terreno en este sentido es comparable a un nombre. El nombre posee sonido y significación; el cuerpo, en cuanto materia viviente,

5. El reflejo trinitario, expuesto en nota anterior, que se manifiesta en el Universo a través del modus, la species y el ordo, podemos explicarlo de la. siguiente manera; el Modus alude a la existencia, a lo. esencia y a la unidad de la cosa. Ser, equivale a ser uno (multiplicidad en la temporalidad); es el modo de ser de las cosas que para ser en pleritud, pasan continuamente al no ser. Esto es expresión de la crofunda jiqueza del Creador. A su vez la perfección de El se expresa en el modus, como mensura (medida). La mensura indica los límites y términos a los seres porque esencialmente el ser de los objetos es distinto del ser. del Creador; no son en el mismo modo. El Creador prefija el modo de ser de las cosas. En relación con el modus, está la forma (species) o hermosura. La forma es una propiedad diferencial o principio de distinción y por la que se da la semejanza con el arquetipo (logos de Dios) con que está modelada la esencia de la cosa. Dios como Forma de las Formas cultiva, distingue y adorna los objetos; en este sentido la forma es inmanente y trascendente. También como principio de distinción, la forma origina el número. El número constituye la ley de las cosas y por lo que los entes quedan sujetos al ritmo y al nimero; esto da lugar a la armonia, que constituye la estructura racional del cosmos. Confróntese $D e$ Ordine, en Obras cit. 
es una especie de sonido que toma forma con armonía intrínseca. Si este equilibrio se rompe o si se descompone tal sonido, se pierde la significación, adviene la muerte del hombre ${ }^{6}$.

b) Breve bosquejo de una teoria de la sensación.

En base a las determinaciones expuestas ${ }^{7}$ se vislumbra una teoría de la sensibilidad en general ${ }^{8}$. El alma en su segundo grado de realidad da lugar a la sensación (los sentidos) en el cuerpo terreno; los miembros de este cuerpo están llenos, digámoslo así, del alma que los cubre. En una palabra lo hace sensitivo. San Agustín en las "Confesiones" los denomina aduana de los sentidos o también puertas. Los sentidos serían medios de los que se sirve el alma para percibir, conformando sus propios y peculiares órganos ${ }^{9}$. Estos son cinco: la vista, el oído, el olfato, el gusto y el tacto. Dentro del peculiar accionar de cada uno de ellos el filósofo delimita dos niveles: a) de la sensación, b) de la percepción. En un sentido general sensación es la simple afección del cuerpo terreno; es el mero padecer en cuanto éste es algo viviente (pasión del cuerpo). La percepción implicaría el darse cuenta de este padecer. A través de los cinco sentidos el alma es consciente del cambio en la proporción armónica del cuerpo terreno; la pasión del cuerpo cuando se conoce a sí misma, es percepción. Este elemento percepción es sumamente importante ya que descubre el fundamento último de toda relación del cuerpo terreno con su ámbito circundante: la propia conciencia. Toda posibilidad o modo de ser tiene su referencia en la conciencia humana. Sensación y percepción, entonces, para el cuerpo terreno, son un padecer consciente de sí mismo. Sin llegar a mostrar lo que constituiria el alma para sap Agustín - nuestro tema es el cuerpo- por lo expuesto nos damos cuenta que el alma es una entidad de naturaleza muy distinta del cuerpo terreno pero que, sin embargo, mora en él. Este morar ori-

6. El concepto de ordo podemos sintetizarlo como aquello que hace que cada cosa ocupe el lugar que le corresponde en el conjunto de los seres: "Ordo est -inquit- per quem aguntur omnia quae Deus constituit" (De Ordine, I, X, 28). Similitud con la justicia cósmica de los filósofos griegos. Para San Agustín la máxima proporción armónica se da en la Santísima Trinidad: el Padre, la Unidad; el Hijo. la Igualdad y el Espíritu Santo, la Armonía entre la Unidad y la Igualdad.

7. Cfr. De quantitate animae, en Obras cit., Caps. I, 2; II, 3; III, $4 ;$ IV, 6 ;

8. Cfr. idem anterior, VI, 10; XIV, 24; XV, 26; XVII, 29; XXI, 35 ; XXII, 38; XXIV, 46; XXXIII, 70, 71, 73 .

9. Cfr. Las Confesiones, en Obras cit., Libro $\mathbf{X}$, Caps. VII y VIII. 
gina la vida en el cuerpo, como hemos visto, y éste oficia como instrumento de ella. La comunicación o conexión entre entidad invisible (alma) y lo visible (Universo), se efectúa a través de los sentidos. El alma, sin embargo, posibilita o brinda en su relación con el Universo visible, lo que éste manifiesta de validez universal y de imperecedero o inmaterial; es capaz de entresacar su constitucional inteligibilidad. Pero esta inteligibilidad, insistimos, se traduce en el alma a través del dato del material sensorial (función conectiva de la sensación). Inmediatamente se asciende al segundo grado de cognoscibilidad: la percepción. San Agustín en su noción de percepción nos propone una idea que ha sido esencial en el desarrollo cultural de Occidente, a saber, que en cierta manera el principio existencial y óntico de los entes reside en la propia conciencia cognoscitiva o interioridad. Así nos expone ${ }^{10}$ que a veces, a diferencia de lo que ocurre en la propia percepción, existen conocimientos que no me los han brindado estrictamente las impresiones tal como ocurre cuando la vista percibe el humo; el concluir la razón que existe el fuego como causa sin llegar a percibirlo, implica para nuestro filósofo una modalidad de conocimiento que salta por sobre el mero nivel sensible para elevarse a un tipo de aprehensión que el propio material sensorial es incapaz de brindar. Como se puede apreciar existe el afán de hacer resaltar cierta formalidad que podemos denominar "a priori" (sin tener el término una acepción rigurosamente kantiana) por sobre lo simplemente exterior, insinuándose una manera de pensar que luego será retomada por Descartes hasta desarrollarse casi plenamente en la reflexión filosófica del criticismo. En cierto modo san Agustín nos ofrece una dialéctica entre el conocimiento sensorial, en sus modos sensitivo y perceptivo, y el conocimiento racional, verdadero y universal, que constituye propiamente la ciencia. En verdad nada novedoso, podría objetarse, pero la originalidad radicó en plantear la propia intimidad humana, el yo, como fundamentante del conocimiento ${ }^{11}$.

10. Cfr. De quantitate animae, en Obras cit., Cap. XXIV, 45.

11. Resiciecto al conocimiento, podemos indicar que para San Agustín se da: a) un conocimiento sensitivo; este se refiere a los objetos exteriores que en cierta forma producen impresiones por la acción o actividad del alma; el cuerpo por la acción del alma, recibe impresiones de los cuerpos exteriores. El alma no es afectada pasivamente por las impresiones corpóreas sino que activamente forma imagen de ellas (verbo sensible) a solicitud de los objetos causadores. En tercer término dentro 
Las consecuencias que podemos extraer de este pequeño bosquejo de su teoría de la sensibilidad, se las debe relacionar con una determinación que sintetizábamos más arriba en el sentido de que el cuerpo humano terreno es un ser-para aquí y ahora. De lo expuesto, ya sean las determinaciones que transcribíamos al comienzo del trabajo o de nuestro bosquejo de una teoría sobre la sensibilidad en general, podriamos extractar la siguiente formulación primaria: el cuerpo humano terrestre de cada uno de nosotros es una forma expresiva espacio-temporal cuya esencial significación consiste en su ser-para o en su instrumentalidad apta para el alma.

II) Perspectiva filosófica; modo racional o inteligible (esencialización del dato).

Esta formulación primaria, que implica una primera aproxima-

de esta esfera sensitiva del conocer luego de la sensación y la imagen, el alma prosigue su labor cognoscitiva refiriendo las sensaciones a un sentido central interior que las hace percibirlas como mias, para luego depurarlas (concepto) y finalmente conservarlas en la memoria (Cfr. $D e$ Trinitate, en Obras cit., XI, I, 2). b) Conocimiento intelectivo; el alma posee otro tipo de conocimiento que la eleva por sobre los animales: el racional que produce la ciencia (scientia). El conocimiento racional se elabora desde una ratio inferior cuya órbita es el mundo sensible y temporal, y desde una ratio superior que considera las verdades y razones eternas, las ideas inmutables y las cosas absolutas (sapientia). La sabiduría consiste en la comprensión de las esencias de las cosas conforme a las verdades inmutables (incommutabilia vera), fundamento de nuestra certeza. Pero entre la razón humana y las cosas divinas o razones eternas, se da una desproporción ontológica por lo que se hace necesaria la iluminación divina. Esta iluminación se la puede considerar activa por parte de Dios y pasiva por parte del hombre. Dios es la fuente de la verdad: "Deus intelligibilis Lux, in quo et a quo et per quem intelligibiliter lucent quae intelligibiliter lucent omnia" (Soliloquia, en Obras cit., I, I, 3). Cuando hablamos de iluminación pasiva surgen dificultades en el sentido de que no considera la acción de Dios sobre el entendimiento humano como la operación de un intelecto agente; el intelecto agente siempre ejerce la acción vital de la intelección, pero, a través de la luz divina, la inteligencia ve las razones eternas y las ideas en Dios. Dentro de este plano cognoscitivo, debemos aludir necesariamente, a la certeza. La certeza ante la duda es la propia existencia: "Quandoquidem etiam si dubitat, vivit, si dubitat, unde dubitat, meminit, si dubitat, dubitare se intelligit, si dubitat, certus esse vut, si dubitat, cogitat, si dubitat, scit, se nescire, si dubitat, iudicat non se temere consentire oportere". (De Trinitate, $\mathrm{X}, \mathrm{X}, 14)$. Aquí entroncamos con el rasgo esencial del conocimiento agustiniano: su interiorismo; el conocimiento de sí mismo es el principio de la sabiduría (sapientia). Para este punto en especial cfr. E. Gilson: "Introduction a L'Etude de Saint Augustin". París, 1949, 1ra. Parte Caps. IV y V. Esta clásica obra conviene tenerla siempre presente. 
ción al fenómeno cuerpo humano terrestre, corresponde al primer modo de la perspectiva filosófica agustiniana y que consiste en una descripción de lo sensible o lectura primaria (dato) de lo real que se considera. Observamos que si bien el cuerpo humano terrestre consiste en una forma expresiva concreta o espacio-temporal, sin embargo, goza de algunas determinaciones universales propias de lo corpóreo en general. En "De la cuantidad del alma", Capítulo III, $4^{12}$ refiriéndose a esto corpóreo, lo explicita como aquello que es esencialmente "largo, ancho y poderoso". También en el mismo texto, Capítulo IV, 6, indica lo que es cuerpo como lo que posee "longitud" "latitud" y "profundidad". De esta manera lo corpóreo en general y por ende cada cuerpo en particular al determinarse como poseyente de "longitud", "latitud" y "profundidad", expresan una nota universal: la extensión. Lo esencial de lo corporal es entonces la extensión. Encontramos aquí un claro antecedente de la res extensa cartesiana formulada en el s. XVII. Ahora: ¿qué significa para san Agustín "longitud", "latitud" y "profundidad" o sea la propia extensión? Su respuesta ocupa en "De la cuantidad del alma" aproximadamente cinco capítulos donde se recurre al razonamiento geométrico quizá como elemento intermedio entre lo sensible (dato) que ya expusiéramos, y la nueva instancia o paso a la esencialización del mismo; ingreso al modo racional de considerar el ente. Si enfocamos desde este punto de vista la "longitud" como primera manifestación de la extensión observaremos, dice el filósofo, que ésta en su estado puro, o sea, separada de la "latitud" y la "profundidad", no la encontramos en ningún cuerpo; solo la puedo concebir así por medio del entendimiento. En este sentido podemos hablar de "longitud" pura como expresión de una línea infinita y cuya prolongación no constituyera nunca propiamente una figura. De aquí pasa, precisamente, al concepto de figura que lo delimita como "el espacio cerrado por una o varias líneas" ${ }^{13}$. La "figura perfecta" es aquella en la que su extremidad equidista en todas sus partes del centro. Conectada con esta idea de centro, llega a una noción geométrica muy importante para la posterior elucidación del cuerpo humano terrestre: la definición de punto. Punto es lo que ocupa el centro de una figura. Inmediata a esta circunscripción da la idea de signo. Signo, dice, es el principio o el

12. En Obras cit.

13. Idem anterior, Cap. VIII, 13. 
fin de la línea; algo sin partes o también lo que inmaterialmente designa el centro de una figura (señal). Entonces, el signo es una señal sin partes y el punto, subsumido bajo este concepto de se$\tilde{n a l}$, es una señal no material que ocupa el centro de la figura ${ }^{14}$. Quizá se pueda ver aquí a través de este aparente e intrincado razonamiento geométrico, que se han vertebrado ciertas propiedades espaciales universales que constituyen la esencialidad de lo corpóreo en general. Así el punto, que posibilita luego la longitud pura (línea infinita) y que a su vez por sus múltiples intersecciones finaliza delimitando el espacio que constituye la figura, es el átomo inteligible, digámoslo así, de todo to extenso. Pero esta unidad mínima de comprensión inteligible, no posee una realidad empírica o visible sino una realidad mental. Entonces, todo lo que constituye el material de los sentidos o sea los objetos aparienciales, es como una especie de relleno, cobertura o "hinchazón" de aquellas estructuras inteligibles primarias y esenciales que el modo de conocimiento matemático nos revela. Pero hay más; creemos que existe una profunda relación entre el concepto signo (señal sin partes) y precisamente el de punto como señal que ocupa el centro de la figura. El signo al ser una señal sin partes es, para Agustín, algo que no posee contenido sensible sino mera relación, proporción o forma armónica que expresa una perspectiva. El punto como determinada especie de signo -el que ocupa el centro de una figura-, constituye esencialmente (aunque en lo sensorial se den puntos materializados) el nudo referencial de sentido de toda una estructura óntica. Curiosamente entonces el cuerpo humano terrestre al ser un ente o figura materializada significativa, expresiva, espacio-temporal y portadora de un atributo inherente, la extensión, refiere su estructura inteligible desde un punto concentrador (centro de la figura) inextenso: el alma. Lo cuantificable, en este caso el cuerpo humano terrestre, adquiere su significación desde lo que no posee cantidad. ¿Quién descubre esta esencialidad? Precisamente la razón, al demostrar que no existe cuerpo sin longitud, latitud y profundidad, y que, además, ninguna de ellas puede, en un cuerpo, hallarse sin la otra. Sin embargo el alma con su peculiar "ojo interior" es capaz de visualizar inteligiblemente hasta una linea unidimensional. El alma por consiguiente, posee una naturaleza simple similar al punto que es señalador sin partes, que es cen-

14. Cfr. ídem. Caps. VIII, 13; XI, 18. 
tro de la figura y que constituye, por sobre todo, una forma in-formadora condensante de sentido. Decimos que todo esto se ha visto, para san Agustín, a través de la luz de la inteligencia; el punto, la línea, la latitud en sí mismas, se descubren no con "ojos corporales" sino con aquel "ojo interior" que descubre lo inmaterial.

Decíamos que, según san Agustín, en la primera aproximación de éste al sentido del cuerpo humano terrestre, el cuerpo era cierta forma expresiva espacio-temporal cuya esencial significación consistia en su ser-para o en su instrumentalidad apta para el alma. Si ahora intentamos delimitar en la segunda instancia expuesta (parte II) desde una visualización esencial de lo real derivada del profundo mirar interior (espectáculo de la razón) el concepto de cuerpo humano terrestre, diremos que lo concibe como una partícula de extensión cuya forma externa se estructura a partir de un centro interior inextenso: el alma.

III) Perspectiva teológica; hermenéutica religiosa fundamentante (absorción de los modos filosóficos anteriores en la Revelación Divina).

Al decir "partícula de extensión cuya forma externa se estructura a partir de un centro interior inextenso: el alma", existiria cierta incompatibilidad entre la "extensión" corporal y su propio fundamento el centro "inextenso" o alma. Dos entidades distintas, lo extenso y lo inextenso y donde la primera está en función de la segunda. Esta contraposición, dep̧ivada de la reflexión filosófica integrada por dos modos de lectura de la realidad, se intenta resolver ahora por el camino de una hermenéutica teológica de fundamentación cristiano-católica. Para san Agustín, en este sentido, existen dos fuentes desde donde se nutre la sabiduria: la Palabra Revelada y el propio Universo como conjunto de los entes. En la primera, la Palabra, el Logos divino, se explicita y encarna en la témporo-espacialidad (aparición histórica de Cristo) derivando en consecuencia, una transformación óntico-ontológica de la naturaleza de lo real visible. Este hecho debe ser objeto de aceptación y reflexión. En la segunda fuente, lo creado es señalador de algunos indicios del propio Creador que lo sostiene en su consistencia, hecho vislumbrado desde lo ínfimo a lo máximo. No existe entonces 
disociación entre la Fe y la Razón. La Fe posee como dato primario la Sagrada Escritura que es inequívoca; la Razón posee como dato primordial el ser del que descubre sus primeros principios y estructuras. Ambos datos, el revelado y el descubierto, confluyen en un único y fontal Logos Divino (la Verdad Absoluta) ${ }^{15}$. Desde esta perspectiva fundamentante se culmina la reflexión sobre la naturaleza del cuerpo humano terreno, y decimos "cuerpo humano terreno" - tal como se ha expresado siempre hasta aqui- porque esie nuestro cuerpo sólo es uno de los modos de ser del cuerpo del hombre. Desde esta nueva óptica abarcante, quizá, se intenta superar la dualidad apuntada de cuerpo y alma. Así el alma es la parte más noble del hombre y el cuerpo su parte inferior; ambas constituyen el hombre. El alma es el hombre interior y el cuerpo el hombre exterior. En realidad son dos hombres siendo lo uno y lo otro lo que expresan un hombre. Como puede apreciarse este dualismo planteado en la propia hermenéutica religiosa es consecuencia de influencias dominantes platónicas. Teniendo como horizonte el tono de realidad expresado, vayamos al problema que entra-

15. La Fe purifica y esclarece los ojos del alma: "Et ideo est nocessario purgatio mentis nostrae, qua illud ineffabile ineffabiliter videri possit; qua nondum praediti fide nutrimur, et per quaedam tolerabiliora, ut illud capiendum apti et habiles efficiamur, itinera ducimur. "( $D e$ Trinitate, I, I, 3). Mediante la purificación el alma se eleva por encima de las cosas sensibles y llega a las inteligibles: "Ut ergo ab huiusmodi falsitatibus humanus animus purgaretur, sancta scriptura parvulis congruens, nullius generis, rerum verba vitavit, ex quibus quasi gradatim ad divina atque sublimia noster intellectus velut nutritus assurgeret. "( $D e$ Trinitate, en Obras cit., I, I, 3). En este sentido la razón ayuda a descubrir lo inteligible de los misterios pero esta tiene un límite: "Quod ergo intelligo, id etiam credo: at non omne quod credo, etiam intelligo" (De Magistro, en Obras cit., II, 37). La fe no como término sino como principio; ésta ayuda a entender y es regla en la investigación sobre los misterios: "Tune agnoscemus quam vera nobis credenda imperata sint, quamque optime et saluberrime apud matrem Eclesiam nutriti fuerimus, quaeve sit utilitas lactis illius quod apostolus Paulus parvulis se potum dedisse praedicavit". (De quantitate animae, en Obras cit., XXXIII, 76). "Quantum vero attinet ad illam summam, ineffabilem, incorporalem immutabilemque naturam, per intelligentiam utcumque cernendam, nusquam se melius, regente dumtaxat fidei regula, acies humanae mentis exercet, quam in eo quod ipse homo in sua natura melius caeteris animalibus, melius etiam caeteris animae suae partibus habet, quod est ipsa meus: cui quidam rerum invisibilium tributus est visus". (De Trinitate, en Obras cit., XV, XXVII, 49). La fe actúa como suplidora de la naturaleza de la razón relacionando San Agustín ciencia humana y fe: "Aliud est enim (scientia) scire tantummodo quid homo credere debeat propter adipiscendam vitam beatam quae non nisi aeterna est; aliud autem scire quemadmodum hoc ipsum et piis opituletur et contra impios defendatur, quam propio apellare vocabulo scientiam videtur apostolus. "(De Trinitate en Obras cit., XIV, I, 3). 
ña el sentido del cuerpo del hombre en esta última y culminante visualización.

Diremos en principio que existe una profunda relación entre cuerpo y tiempo o cuerpo humano y temporalidad. La realidad o constitución óntica del cuerpo del hombre se determina, en todos los casos, desde sucesos ubicados en las profundidades del tiempo. Estos sucesos fundamentales, casi arquetípicos, se entretejen con tiempo pasado: a) al crear Dios al hombre; b) al desobedecer éste a su propio creador. En ambos casos estos hechos pasados, determinaron dos formas cualitativas divergentes de cuerpos humanos. En el primer caso, creación del hombre, el cuerpo entraña una serie de notas distintivas inherentes, que lo separan de la naturaleza del cuerpo posterior a la caída. El acontecimiento de la infracción humana acarreó sobre sí, la mutación del cuerpo adánico por el que actualmente poseemos. Otro de los sucesos fundamentales arriba aludidos, se trama con tiempo presente: a) al encarnarse Dios; b) al resucitar Jesús como primicia de los cuerpos de los hombres. Este último hecho en sus dos secuencias, Encarnación y Resurrección, determina la posibilidad de elegirnos como cuerpo inmortal no sufriente o como cuerpo inmortal padeciente. En ambos casos el cuerpo humano terreno en su constitución ha sido (para Cristo como único ser resucitado) y será (para los que aún no han sufrido la transformación) de naturaleza diferente a los cuerpos anteriores. Por último, otro de los sucesos determinativos del tipo de corporalidad a adquirir, está entretejido de aproximante temporalidad futura: a) cuando se dé la resurrección de Ios muertos; b) cuando se realice el Juicio Final. Durante este tiempo adveniente el cuerpo humano terreno tomará una entidad similar a la de Cristo resucitado conllevando en sí la posibilidad ya concretada de transformación o no, en un cuerpo sufriente eterno. Decíamos, entonces, profunda relación entre cuerpo humano terreno y temporalidad; temporalidad que, como puede apreciarse, se ubica entre hitos pasados, presentes y futuros. Asi san Agustín, en su esencial hermenéutica religiosa platónico-cristiana, relaciona indisolublemente tiempo y metamorfosis corporal. En tres momentos del tiempo tres metamorfosis somáticas: la primera correspondiente a los sucesos Paraíso y Caída; la segunda Caída-Resurrección (en un ser se operó) y tercera la que pertenece a la Caída-Resu- 
rrección de todo el género humano que habría concretado ya su posibilidad de vida o muerte eterna. En este sentido san Agustín ve al hombre como algo que se "viste" de distintos modos. Las distintas transformaciones o metamorfosis corporales son simplemente, entonces, "vestimentas"; en este sentido dice el filósofo "vestímonos" en primer término, a imagen y semejanza del hombre terreno (traje corporal de pecado y muerte); en segundo término. a imagen y semejanza de Jesús como hombres celestiales regenerados por su propia virtud obrante.

Visto el esquema anterior, pasamos ahora a determinar analíticamente las determinaciones del cuerpo del hombre en relación con esta temporalidad pasada, presente y futura.

\section{a) Características del cuerpo humano antes de la Caída.}

Dios, para san Agustín, es el creador del alma y del cuerpo ${ }^{16}$. Este lo forma del "polvo o "limo" de la tierra al que infunde un "soplo". De acuerdo a esto las criaturas poseen dos formas, una exterior y otra interior. La forma interior es la que estructura o predetermina las formas naturales de los cuerpos. Especie de potencia

16. Dios crea su obra: a) en un solo instante (simul) y b) la conserva y la asiste a través de los siglos; creación simultánea y sucesiva" "Hoc exemplo qui potest intellegat materiam rerum primo factam et apellatam caelum et terram, quia inde facta sunt caelum et terra, nec tempore primo factam, quia formae rerum exserunt tempora, illa autem erat informis; iamque in temporibus simul animadvertitur, nec tamen de illa narrari, aliquid potest, nisi velut tempore prior sit, cum pendatur extremior, quia profecto meliora sunt formata quam informia, et praecedatur aeternitate creatoris, ut esset de nihilo, unde aliquid fieret". (Las Confesiones, en Obras cit., XII, XXX, 41). También, refiriéndose a la consistencia de las cosas dice: "Quid si dicat et allius, caelum et terram quidem invisibilem visibilemque naturam non indecenter appellatam, ac per hoc universam creaturam, quam fecit in sapientia, id est in principio, Deus, huiuscemodi duobus vocabulis esse comprehensam; verum tamen quia non de ipsa substantia Dei, sed ex nihilo cuncta facta sunt quia non sunt id ipsum, quod Deus, et inest quaedam mutabilitas omnibus, sive maneant, sicut aeterna domus Dei, sive mutentur, sicut anima hominis et corpus, communem, sed certe formabilem - unde fieret caelum et terra, id est invisibilis atque visibilis iam utraque formata creatura- "(Las Confesiones, en Obras cit., XII, XVII, 25). Podemos agregar: "Nonne tu, Domine, docuisti me, quod, priusquam istam informem materiam formares atque distingueres, non erat aliquid, non color, non figura, non corpus, non spiritus? Non tamen omnino nihil; erat quaedam informitas sine ulla specie". (Las Confesiones, en Obras cit., XII, III, 3). Respecto a la hipótesis de las razones seminales relacionadas con la Creación, confróntese De Trinitate, III, IX, 17. 
obrante que se deriva de un poder intrínseco al Creador. Mención a la omnipresencia de Dios que se manifiesta por medio de estas especies de "entelequia" si lo formuláramos a la manera aristotélica. En este período paradisíaco los cuerpos eran cuerpos animales no espirituales, que, inciuso, se alimentaban, pero, no morian. Poseían a su vez un alma viviente y no un espíritu vivificante. El primer cuerpo de Adán fue un cuerpo animal no sometido a la muerte y la naturaleza de su carne, no era la misma que ésta terrena; la adquiere después de la caída. En este tiempo Dios creó al hombre "recto", aunque sin determinar la forma particular en que cada uno habíamos de vivir; también seríamos de una condición seminal y fecunda ("creced y multiplicaos", Génesis, 1,28. En esta existencia del Edén se supone la inexistencia de la corrupción y del cambio, gozando el hombre de una perfección permanente, consecuencia de la acción divina que consideró "buena" la obra.

\section{b) Suceso de la caida y sus consecuencias para el cuerpo.}

Según san Agustín el suceso de la caída consistió fundamentalmente en un hecho de naturaleza ética, la desobediencia; el pecado no fue por la maldad del fruto sino que la transgresión consistió en desobedecer; con esta desobediencia se inauguró el fenómeno omnipotente de la muerte que señorea en nuestra dimensión terrena. El obispo de Hipona nos expresa que la desobediencia consistió en un primer "desamparo" del alma respecto a Dios (alejamiento primario) por lo que la divinidad, automáticamente, cumpliendo su insita ley, "desampara" al alma (vergüenza por la desnudez de los cuerpos), originándose en este sentido un movimiento rebelde en la carne que comienza a disputar con el alma. O sea, los fines antes convergentes entre lo exterior del hombre "limo" creado, y su "interior", "soplo" vivificador, comienzan ahora a separarse, a ser divergentes. Es como si, según nos interpreta el santo, Adán se constituyera para si mismo en un conflicto, y con él la humanidad, cuya proyección trastoca a todas las cosas creadas, al universo, en forma de abarcante conflagración de los elementos. Puede decirse que se inicia una esencial desproporción al romperse la armonía, en el sentido pitagórico del término, del gran acorde musical instaurado por la divinidad desde el principio. Inauguración de la muerte, decíamos. Este hecho de la muer- 
te en la hermenéutica religiosa que nos movemos, es, a nuestro juicio, un fenómeno esencial, pues en ella lo que le sucede al cuerpo -expresión del alma- indica la naturaleza metafísica del hombre. Asi en su exégesis bíblica nos habla de las tres muertes que se reducen finalmente a dos. La primera sucedió cuando el alma creada desamparó a Dios y a su vez fue desamparada. El alma al alejarse de la fuente de su natural alimento, se debilitó hasta perecer entre las conformaciones de lo exterior, de lo meramente visible. La segunda muerte, reflejo de la primera, sucede cuando el alma desampara al cuerpo por la acción de la temporalidad que inexorablemente conduce a su corrupción. El filósofo aquí habla de la muerte del cuerpo fundamentándose en la sentencia bíblica: "Tierra eres y a la tierra volverás" de Génesis 3,19. Finalmente se puede aludir a una tercera muerte que constituye en realidad la segunda propiamente dicha, ya que la primera y la segunda expuestas, configuran lo que el santo denomina "primera muerte"; las que denominó "primera" y "segunda" entonces, serían meramente sucesos del ciclo mortal desde Adán hasta nosotros. La tercera y última o segunda propiamente dicha, se da si el hombre mediante la acción de la gracia no escapa de ella que es muerte eterna.

Tratando de sintetizar lo esencial del hecho de la caída y de sus derivaciones para la consiguiente conformación del cuerpo del hombre, diremos que éste consistió en ser el factor desencadenante de la inversión de relaciones entre criatura y Creador, al alejarse aquélla de éste mediante un soberbio y falaz ontizarse desde sí misma, hecho que contrarió y contraría permanentemente su esencial entidad inconsistente y derivada.

c) Características del cuerpo derivadas de la transgresión (determinaciones actuales del "cuerpo terreno").

Luego de la desobediencia, se transforma la naturaleza del cuerpo humano paradisíaco en otra trocada y corrompida. En la exégesis de estos pasajes bíblicos, san Agustín sugiere la idea de que el destino del hombre se origina cuando comienza a existir y a residir en él cuerpo mortal; este destino último y peculiar es la muerte. El hombre desde esta perspectiva es una esencial nada que transita entre dos nadas fundamentales: la del barro original 
y la del polvo anonadante. Sin embargo todo adquiere sentido, si somos conscientes de nuestra propia facticidad y dirigimos el mirar a la trascendencia eternizante y universal. El "cuerpo terreno" trae toda clase de molestias, corruptibilidad y pesadumbre. Refiriéndose el filósofo a la pesadumbre, destaca precisamente que una de las notas constitutivas de nuestro cuerpo terreno es el peso (pondus) natural, o sea, eso que hace que la tierra lo llame y lo atraiga hacia sí. Los cuerpos terrenos son como "máquinas" tiradas hacia abajo que se desintegran al partir el alma de ellas; se produce la muerte como efecto necesario de una naturaleza plenamente mudada. Este estado de la corporeidad humana en su corruptibilidad, es trasmisible y afecta a todo el género humano a partir de Adán. La carne posee una serie de necesidades como comer, beber, dormir, dice san Agustín, que se conjuntan con las necesidades o imperfecciones psíquicas consistentes en los diversos estados anímicos, alegría, tristeza, etc., producidos por la propia alma.

Si intentamos extraer una determinación esencial que san Agustín coloque en nuestro cuerpo terreno, diremos - como ya lo enunciáramos- que consiste en el pondus (peso). El peso, en cierta manera, es el causante de la corrupción básica y de ia atadura del hombre a lo que está por debajo, alejándolo del verdadero terruño natural que está en lo alto.

d) Breves caracteristicas del hecho de la Encarnación como suceso central desencadenante de una nueva naturaleza corporal (ingreso de Dios en la historia).

El fenómeno de la ascensión del cuerpo glorioso de Cristo es lo primero que expone san Agustín como auténtica prueba de que Dios puede quebrar, liberar, al cuerpo terreno de la propiedad que anteriormente enunciábamos, el peso. En este portentoso suceso se observa la ruptura de la atracción terrestre, o sea, que una de las determinaciones fundamentales de los cuerpos resucitados, va a ser su ingravidez absoluta. Cristo lo demostró y no debemos olvidar que el suceso de la Resurrección para la hermenéutica teológica agustiniana, es un hecho como el del Paraíso terrenal, arquetípico. Luego de la Resurrección nuestros cuerpos podrán comer y beber tal como se manifiesta en Lucas 24. Cristo adquiere como 
resucitado, un "cuerpo espiritual", o sea, pasa a ser "espíritu vivificante". El filósofo en estas últimas consideraciones prácticamente parafrasea a Romanos 8,28 y siguientes y a 1 Corintios 15, 47 y siguientes. Jesús-Dios al ingresar en la historia, según las palabras del santo, se cubre "vistiéndose de nuestra flaca y débil naturaleza" 17 edificando Dios para sí mismo "una humilde casa de nuestro propio barro" ${ }^{18}$, participando "del traje tosco de nuestra naturaleza" ${ }^{19}$. Sintetizando, y usando la propia cita que Agustín mismo transcribe de Juan 1,14, decimos que "El verbo se hizo carne".

e) Características de nuestro cuerpo futuro luego del suceso de la Resurrección.

La última metamorfosis corporal está determinada también a partir del propio hecho de la Resurreción de Jesucristo. Así para el filósofo las almas bienaventuradas pondrán en cualquier parte sus cuerpos, afirmando $-y$ como puede apreciarse repetidamenteque sus cuerpos serán sin "peso" y "carga". En este sentido los cuerpos terrestres se harán incorruptibles, eternos e inmortales. El cuerpo resucitado será, como se dijo anteriormente, un "cuerpo espiritual" o "espíritu vivificante" que se sujetará con admirable facilidad al espíritu, sustentándose y perseverando en él sin dejar por ello de ser cuerpo.

\section{Algunas conclusiones.}

Expuesto el peculiar mirar de la hermenéutica teológica, creemos conveniente volver a las aproximaciones que efectuábamos en los finales de los puntos I,b y final del II. Primera aproximación $(\mathrm{l}, \mathrm{b})$ : el cuerpo humano terrestre de cada uno de nosotros es una forma expresiva espacio-temporal cuya esencial significación consiste en su ser-para o en su instrumentalidad apta para el alma. Segunda aproximación (II): partícula de extensión cuya forma se estructura a partir de un centro interior inextenso: el alma.

17. Cfr. Las Confesiones, en Obras cit., Libro VII, cap. XVIII.

18. Cfr. idem anterior.

19. Cfr. ibidem; aparte para el desarrollo de este punto III, confróntese De civitas Dei, en Obras cit,, desde el Libro XII, cap. XXIV hasta el Libro XIII, cap. XXIII. 
Del análisis de ambas y de la luz que arroja sobre ellas su propio pensar hermenéutico clásico-cristiano, intentamos la última y tercera aproximación que resulta englobante de las dos primeras y que enunciamos así: el cuerpo humano terreno es un ente extenso cuyo sentido esencial consiste en expresar el desgarramiento y el ingreso a la temporalidad de un ser de semejanza divina, el hombre, cuyas interacciones, lanzadas desde un punto de absoluta libertad de elección, constituyen la dramática historia del desarrollo de un plan de salvación.

RAUL R. IRIARTE

Bahía Blanca (Argentina), julio de 1971. 